\title{
Papers
}

\section{Association between antidepressant prescribing and suicide in Australia, 1991-2000: trend analysis}

\author{
Wayne D Hall, Andrea Mant, Philip B Mitchell, Valerie A Rendle, Ian B Hickie, Peter McManus
}

\begin{abstract}
Objective To examine the association between trends in antidepressant prescribing and suicide rates in Australia for 1991-2000.

Design Analysis of databases of suicide and rates of antidepressant prescribing according to age and sex. Setting Australian Bureau of Statistics data, sales data from the Australian pharmaceutical industry, prescribing data in general practice.

Subjects Men and women aged 15 years and over in 10 year age groups.

Main outcome measures Trends in suicide rates and trends in antidepressant prescribing. Association measured by Spearman's rank correlations.

Results While overall national rates of suicide did not fall significantly, incidence decreased in older men and women and increased in younger adults. In both men $\left(r_{s}=-0.91 ; \mathrm{P}<0.01\right)$ and women $\left(r_{s}=-0.76\right.$; $\mathrm{P}<0.05)$ the higher the exposure to antidepressants the larger the decline in rate of suicide.

Conclusions Changes in suicide rates and exposure to antidepressants in Australia for 1991-2000 are significantly associated. This effect is most apparent in older age groups, in which rates of suicide decreased substantially in association with exposure to antidepressants. The increase in antidepressant prescribing may be a proxy marker for improved overall management of depression. If so, increased prescribing of selective serotonin reuptake inhibitors in general practice may have produced a quantifiable benefit in population mental health.
\end{abstract}

\section{Introduction}

In many developed countries the number of prescriptions for antidepressants increased steeply during the 1990s, after the introduction of selective serotonin reuptake inhibitors (SSRIs). ${ }^{1-4}$ In some countries the increased rate of prescribing coincided with fall in the suicide rate..$^{2-4}$

Research has been carried out to test the hypothesis that increased antidepressant prescribing was partially responsible for this decline. In Sweden between 1991 and 1996 antidepressant prescribing increased steeply after the introduction of the SSRIs in 1990, and the rate of suicides was inversely related to rates of antidepressant prescribing in most age and sex groups. ${ }^{3}$ In another study in Sweden Carlsten et al examined data for 1977-97 (using official mortality statistics) and data on antidepressant use from surveys of sales to pharmacies. ${ }^{2}$ They found that suicide rates declined over the whole study period, but the rate of decline accelerated after the SSRIs were introduced in 1990. In Hungary in 1984-98 antidepressant prescribing rose steeply after the introduction of SSRIs in the early 1990s and rates of suicide declined, despite steep increases in unemployment and per capita alcohol consumption. ${ }^{4}$

Contrary to these positive findings, however, in Italy Barbui et al did not find any association between suicide rates and antidepressant use for 1986-96, during which time SSRIs were introduced. ${ }^{5}$

We examined the association between changes in antidepressant prescribing in Australia for 1991-2000 and changes in rates of suicide. We analysed differences in suicide trends between men and women in different age groups to assess whether age and sex rates in suicide were related to differences between age and sex groups in exposure to antidepressant medication. We also examined any differences between age and sex groups in rates of antidepressant prescribing and whether these were related to trends in suicide rates in these age and sex groups.

\section{Methods}

We used a quasi-experimental approach to analyse associations using prospectively collected data sets. ${ }^{6} \mathrm{We}$ used information on per capita alcohol consumption, unemployment rates, and method of suicide to assess the plausibility of competing explanations of any associations.

Suicide-The Australian Bureau of Statistics provided data on the age and sex in all cases of suicides for each year for 1986-90 and 1996-2000. ${ }^{7}$ We calculated annual mortality for men and women in eight age groups $(15-24,25-34,35-44,45-54,55-64,65-74$, $75-84$, and $\geq 85$ years) using population estimates.

Antidepressant use-We estimated trends in prescribing of antidepressants by combining data on sales with estimates of the proportion of antidepressants that were prescribed to men and women in the eight age groups. Data on total sales of antidepressants were obtained from IMS Health Australia, the leading international provider of data on drug use to the pharmaceutical and healthcare industries. We converted data (retrieved as kilograms of active ingredient)
Office of Public Policy and Ethics, Institute for Molecular Molecular

University of Queensland, Brisbane, Queensland 4072, Australia Wayne D Hall professor and director School of Public Health and Community Medicine,

University of New South Wales, Sydney, New South Wales 2052, Australia

Andrea Mant associate professor Valerie A Rendle research assistant

School of

Psychiatry,

University of New

South Wales,

Randwick, New

South Wales 2031, Australia

Philip B Mitchell professor and head of psychiatry

beyondblue: the national depression initiative,

Melbourne, Victoria 3122, Australia

Ian B Hickie professor of community psychiatry

Drug Utilisation Subcommittee, Department of Health and Ageing Canberra 2601, Australia

Peter McManus committee secretary

Correspondence to: A Mant

a.mant@unsw.edu.au

bmj.com 2003;326:1008 
to defined daily dose (DDDs). This figure is based on the assumed average daily dose of the drug when it is used by adults for its main indication. ${ }^{8}$ The estimated age and sex profile of people prescribed antidepressant drugs was derived from a series of large scale surveys of prescribing by Australian general practitioners, who account for the bulk of such prescribing in Australia. ${ }^{9-11}$ Information collected from these surveys was encounter based with randomly sampled general practitioners (in 1990-1, 1995, and 1998-2001) recording prescription practices over a set number of consecutive encounters. The level of antidepressant prescribing in each age and sex group was expressed as the estimated defined daily doses per 1000 population per day (DDD/1000/day).

Statistical analyses-We used Spearman rank correlations $(r)$ to assess the associations between trends in rates of suicide and trends in antidepressant prescribing for each sex. The trend in suicide within each age group was measured by the difference between the suicide rates per 100000 people in two five year periods (1986-90 and 1996-2000). We assessed the trends in antidepressant prescribing by the mean of the DDD/1000/day in each age group across the three large general practice surveys and by the difference between the DDD/1000/day in 1991 and that in 2000 . The former was a measure of each group's total exposure to antidepressants; the latter was a measure of the change in rate of antidepressant prescribing for the group over the study period.

\section{Results}

Trends in suicide and antidepressant prescribing-The total suicide rate for Australian men and women did not change between 1991 and 2000 because marked decreases in older men and women (table 1) were offset by increases in younger adults, especially younger men. ${ }^{7}$ Between 1991 and 1998 the rate fluctuated between a low of 11.8 in 1993 and a high of 14.7 per 100000 in 1997, when there were 2723 suicides (2146 men and 577 women). ${ }^{7}$ Table 2 shows the trends in DDD/1000/day for each age group separately for men and women. Exposure to antidepressants was generally higher for women than men in all age groups and increased markedly for both men and women over the study period, with the largest increases among older adults.

Association between suicide and antidepressant prescribing-Among both men $(r=-0.91 ; 95 \%$ confidence interval -0.57 to -0.98$)$ and women $(r=-0.76$; -0.12 to -0.95$)$ the largest declines in suicide occurred in the age groups with the highest exposure to antidepressants across the study period (fig 1 ). There was also a significant inverse association between change in DDD/1000/day and change in suicide in women $(r=-0.74 ;-0.07$ to -0.95 , fig 2$)$. The latter correlation was not significant in men but the confidence interval around it was consistent with a large negative correlation $\left(r_{s}=-0.62 ; 0.36\right.$ to -0.80 ; fig 2).

\section{Discussion}

We found a steep increase in antidepressant prescribing in Australia from 1991 to 2000, which, unlike in earlier studies, was not accompanied by a decline in overall rates of suicide because there was a large increase in suicide in young people over the same period. ${ }^{7}$ There was, however, a strong association between the groups with high exposure to antidepressants and the groups in which the rate of suicide fell. The groups with the highest antidepressant exposure showed the largest declines in suicide.

\section{Making causal inferences from ecological data}

Because we have studied ecological rather than individual level data, correlations between overall trends in suicide rate and antidepressant prescribing do not necessarily mean that antidepressant prescribing has reduced rates of suicide in depressed patients. Ecological data can support causal inferences if they

Table 1 Rates of suicide (per 100000 people) in Australia by sex and age, 1986-2000

\begin{tabular}{|c|c|c|c|c|c|c|}
\hline \multirow[b]{2}{*}{ Age (years) } & \multicolumn{3}{|c|}{ Men } & \multicolumn{3}{|c|}{ Women } \\
\hline & $1986-90$ & 1991-5 & $1996-2000$ & 1986-90 & 1991-5 & $1996-2000$ \\
\hline $15-24$ & 24.83 & 26.05 & 24.81 & 4.75 & 5.35 & 5.74 \\
\hline $25-34$ & 28.90 & 30.32 & 35.73 & 6.69 & 6.60 & 7.52 \\
\hline $35-44$ & 25.04 & 26.17 & 30.49 & 7.01 & 7.10 & 8.34 \\
\hline $45-54$ & 24.09 & 24.77 & 23.78 & 8.31 & 7.17 & 6.94 \\
\hline $55-64$ & 25.13 & 22.75 & 20.68 & 8.07 & 7.04 & 6.00 \\
\hline $65-74$ & 27.32 & 23.24 & 21.91 & 8.36 & 5.95 & 5.78 \\
\hline $75-84$ & 36.53 & 30.37 & 28.68 & 8.13 & 7.63 & 5.74 \\
\hline$\geq 85$ & 44.02 & 40.49 & 37.45 & 6.90 & 5.53 & 4.09 \\
\hline
\end{tabular}

Table 2 Estimated use of antidepressants (defined daily dose/1000 people/day) by sex and age

\begin{tabular}{|c|c|c|c|c|c|c|}
\hline \multirow[b]{2}{*}{ Age (years) } & \multicolumn{3}{|c|}{ Men } & \multicolumn{3}{|c|}{ Women } \\
\hline & 1990-91 & 1995 & 1998-2001 & $1990-1$ & 1995 & 1998-2001 \\
\hline $15-24$ & 1.2 & 2.7 & 14.3 & 3.2 & 7.9 & 30.7 \\
\hline $25-34$ & 3.5 & 11.8 & 26.4 & 10.4 & 22.2 & 58.0 \\
\hline $35-44$ & 7.6 & 15.8 & 36.4 & 14.6 & 29.5 & 73.1 \\
\hline $45-54$ & 10.9 & 20.0 & 43.0 & 24.2 & 47.2 & 86.7 \\
\hline $55-64$ & 14.5 & 23.6 & 44.8 & 32.9 & 50.9 & 87.8 \\
\hline $65-74$ & 24.1 & 29.6 & 47.5 & 40.0 & 60.5 & 103.6 \\
\hline $75-84$ & 29.6 & 38.2 & 61.3 & 45.7 & 67.6 & 114.2 \\
\hline$\geq 85$ & 29.0 & 50.7 & 74.3 & 29.6 & 46.1 & 93.4 \\
\hline
\end{tabular}




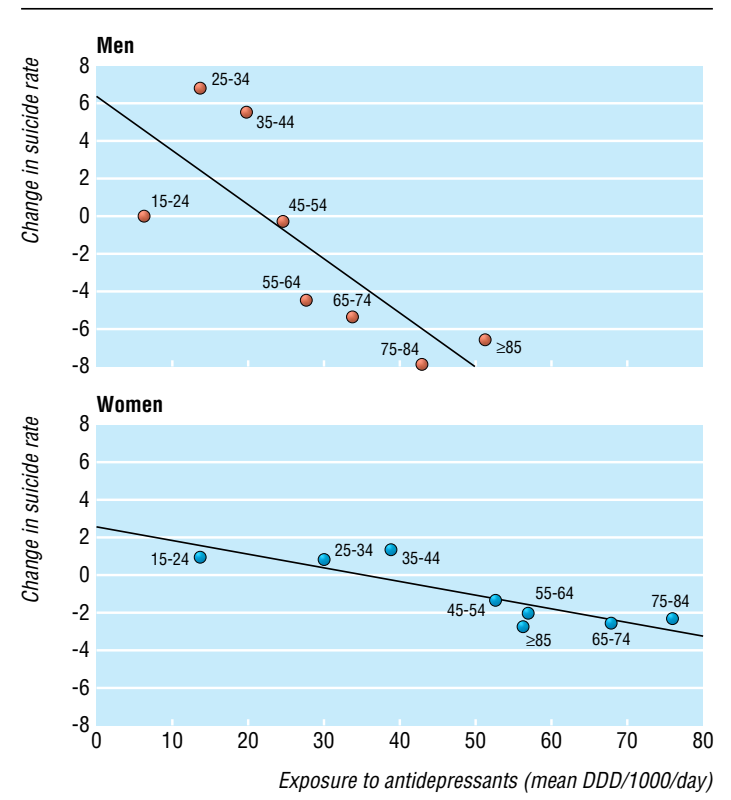

Fig 1 Change in suicide rate by level of exposure to antidepressants in each age group among men and women aged $>15$ years

are supported by other evidence, both negative and positive. Negative evidence supports the implausibility of alternative explanations of the association. Positive evidence supports a causal explanation of the observed association-for example, by supporting a mechanism that would explain the association.

\section{Excluding plausible alternative explanations}

Systematic errors in the data on suicide or antidepressants may have biased the results. Suicides, for example, are under-reported, and there are likely to be errors in using general practice prescription profiles to estimate sex and age differences in use from sales data. It is unlikely, however, that under-reporting of suicide
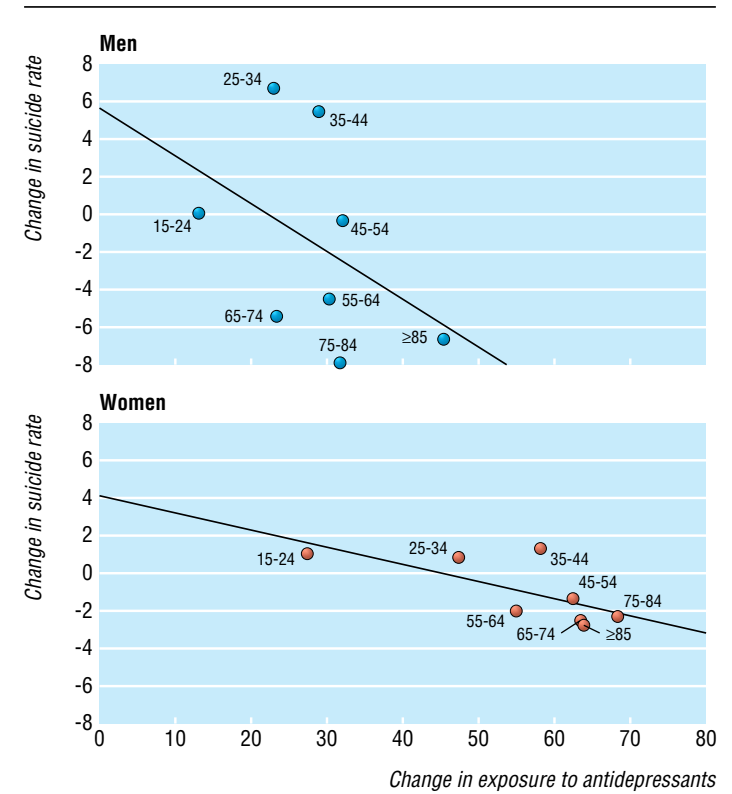

Fig 2 Change in suicide rate by change (from 1991 to 2000) in level of exposure to antidepressants for each age group among men and women aged $>15$ years should have changed over time or that such under-reporting, or any errors in the general practice survey data, would both vary by age and sex in the ways required to explain the patterns in our data.

Trends in risk factors for suicide, such as unemployment and per capita alcohol consumption, may explain the decline in suicide. Per capita alcohol consumption (calculated from sales data) shows a substantial decline in the early 1990s in Australia, but it remained steady throughout the remainder of the 1990 s. $^{12}$ This was mirrored by trends in alcohol related injuries. ${ }^{13}$

Among older men unemployment increased during the study period, ${ }^{14}$ excluding this as an explanation for the reduction in suicide among men in this age group. Increases in unemployment in younger men may have contributed to the rising suicide rate in this age group. ${ }^{15}$ There is no evidence of marked changes in method of suicide that would explain the different rates of decline in suicide between age groups. ${ }^{7}$ We can also exclude the possibility that the declines in suicide rates reflect education campaigns to reduce suicide because in Australia these campaigns have focused on suicide among young men.

Declining suicide rates in older Australian adults may reflect a general improvement in quality of life among older Australians. This is not supported by surveys of self reported quality of life in Australia in 1981-9 and 1996-7. ${ }^{16}$ There was no change in quality of life over this period and no differences in change in quality of life between older and younger Australians. ${ }^{16}$

\section{Positive evidence for a causal interpretation}

There are several reasons for believing that increased antidepressant prescribing may have contributed to the decline in suicide. Firstly, depression is a risk factor for suicide, and antidepressants reduce suicidal ideation. There is little direct evidence that antidepressants reduce the suicide rate because suicide is rare even among clinically depressed people, and even large clinical trials of antidepressants have had limited power to detect a reduction. None the less, there is reasonable epidemiological evidence that antidepressants reduce suicide rates in depressed patients. ${ }^{17}$

Secondly, the prescription of antidepressant drugs is also often accompanied by other assessments (such as asking about suicide risk, giving information to family members) and clinical interventions (counselling, support, ongoing clinical review). These interventions, in combination with medication, may reduce suicidal behaviour. ${ }^{18}$

Thirdly, the introduction of selective serotonin reuptake inhibitors may have been responsible for increased prescribing and other interventions for depression in primary care. These drugs have a lower rate of sedation, postural hypotension, and cardiac changes, fewer serious drug interactions, and greater safety in overdose than older types of antidepressant. ${ }^{19}$ These characteristics have reduced doctors' reluctance to prescribe such drugs to older patients, ${ }^{20}$ patients with other medical problems or who are using other medications, and working patients for whom sedation is a major limitation. General practitioners are now more likely to prescribe antidepressant drugs without referring patients to a specialist. ${ }^{18}$ 


\section{What is already known on this topic}

There has been a substantial increase in antidepressant prescribing by general practitioners in Australia since the introduction of selective serotoin reuptake inhibitors in the early 1990s

Previous studies have indicated an association between increased antidepressant prescribing and reduced suicide rate

\section{What this study adds}

In Australia the rate of suicide fell in older people, the age group most heavily exposed to antidepressants

Most antidepressants are now prescribed by general practitioners

The association may indicate the improved treatment of depression by general practitioners

Finally, formulations of selective serotonin reuptake inhibitors (for example, one tablet once a day) improve compliance with treatment. While some patients are reluctant to start antidepressant treatment, ${ }^{21}$ experiences with the safety, tolerability, and benefits of selective serotonin reuptake inhibitors may be changing attitudes towards drug treatment for depression, ${ }^{21}$ which may, in turn, have increased treatment seeking and compliance in older men and women. ${ }^{18}$

We think that antidepressant prescribing is a proxy measure for exposure to psychosocial and pharmacological interventions delivered by a general pracitioner for depression, anxiety, and other comorbid psychological disorders. Data from Australian general practice surveys indicate that general practitioners identify a wide range of psychological disorders, provide more non-pharmacological than pharmacological interventions, and, when they use pharmacological treatments, rarely provide them without psychosocial assessment and support. ${ }^{11} 1822$

Recognition of psychological disorders in general practice and general practitioners' use of psychosocial and pharmacological treatments for depression may have improved. ${ }^{23}$ Given these trends in general practice, the association we observed between antidepressant prescribing and suicide may reflect increased recognition, diagnosis, and treatment of depression by general practitioners as much as any pharmacological effects of antidepressant medication. ${ }^{18} 22$ If this proves to be the most plausible explanation of our data, it supports the public policy of encouraging general practitioners to improve community mental health. ${ }^{182324}$

We thank our colleagues on the beyondblue project steering group: Neil Donnelly, Louisa Degenhardt, Robert Goldney, Bill Montgomery, Ian Wilson, and Katherine Duszynski.

Contributors: WDH assisted in preparing the application for funding, developed the approach to data analysis, supervised the data analysis, and produced the first draft of the paper. AM had the original idea for the study, prepared the application for funding, assembled the research team, contributed to the data analysis, assisted in drafting of the paper, and is the guarantor for the study. PBM helped to develop the original idea and to secure funding and contributed to the data analysis and preparation of the final paper. VAR obtained the various data sets used in the analysis, liaised with the custodians of the datasets, undertook the statistical analyses, and assisted in the preparation of the paper. IBH assisted in securing funding for the study and contributed to data analysis, interpretation of the data, and the preparation of the paper. PMcM helped to develop the original idea and contributed to the data analysis and preparation of the final paper.

Funding: beyondblue (the national depression initiative). Strategic Fund of the Vice Chancellor, University of Queensland. IMS Health Australia Pty provided retrospective data at no charge, courtesy of Eli-Lilly Australia Pty. The guarantor accepts full responsibility for the conduct of the study, had access to the data, and controlled the decision to publish.

Competing interests: AM was a consultant on Quality Use of Medicines to Merck, Sharp and Dohme Australia (1997), has been a member of advisory boards for Pfizer and SanofiSynthelabo (1999-2000), and was sponsored to attend Global Health Care 2000 Conference (Eli-Lilly). PBM has received research funding and honorariums in the past five years from several pharmaceutical companies that manufacture antidepressant medications. IBH has received research funding and honorariums in the past five years from several pharmaceutical companies for conduct of general practice training programmes and from Wyeth for participation in international meetings detailing the economic and social costs of depression.

McManus P, Mant A, Mitchell P, Montgomery WS, Marley J, Auland ME. Recent trends in the use of antidepressant drugs in Australia, 1990-1998 Med J Aust 2000;173:458-61.

2 Carlsten A, Waern M, Ekedahl A, Ranstram J. Antidepressant medication and suicide in Sweden. Pharmacoepidemiol Drug Saf 2001;10:525-30.

Isacsson G. Suicide prevention-a medical breakthrough? Acta Psychiatr Scand 2000;102:113-7.

Rihmer Z. Can better recognition and treatment of depression reduce suicide rates? A brief review. Eur Psychiatry 2001:16:406-9

5 Barbui C, Campomori A, D'Avanzo B, Negri F Garattini S. Antidepressant drug use in Italy since the introduction of SSRIs: national trends, regional differences and impact on suicide rates. Soc Psychiatry Psychiatr Epidemiol 1999;34:152-6.

6 Cook TD, Campbell DT. Quasi-experimentation:design and analysis issues for field settings. Chicago: Rand McNally, 1979.

Australian Bureau of Statistics. Suicides, Australia. Canberra: Commonwealth of Australia, 2000. (No 3309.0.)

WHO Collaborating Centre for Drug Statistics. Methodology. Guidelines for ATC classification and DDD assignment. 2nd ed. Oslo: WHO, 1998.

9 Bridges-Webb C, Britt H, Miles DA, Neary S, Charles J, Traynor V. Morbidity and treatment in general practice in Australia 1990-1991. Med J Aust 1992;157(suppl):S1-56.

10 Vagholkar S, Spence J, Charles J. General practice audit as a quality assurance activity. An evaluation of the morbidity and therapeutic index. Aust Fam Physician 1996;25:370-5

11 Britt H, Sayer GP, Miller GC, Charles J, Scahill S, Horn F, et al. General practice activity in Australia 1998-1999. Canberra: Australian Institute of Health and Welfare, 1999. (AIHW Catalogue Number: GEP 2. General Practice Series No 2.

12 Catalano P, Chikritzhs T, Stockwell T, Webb M, Rohlin C-J, Dietze P. Trends in per capita alcohol consumption in Australia, 1990/91-1998/99. Perth: National Drug Research Institute, 2001. (National Alcohol Indicators Bulletin No 4,

13 Chikritzhs T, Stockwell T, Heale P, Dietz P, Webb M. Trends in alcohol-related road injury in Australia, 1990-1997. Perth: National Drug Research Institute, 2000. (National Alcohol Indicators Bulletin No 2.)

14 Australian Bureau of Statistics. Australian social trends 2001. Work-paid work: trends in employment population ratios. www.abs.govau/ausstats (accessed 13 Aug 2002)

15 Morrell S, Page A, Taylor R. Unemployment and youth suicide. Economic and Labour Relations Review 2001;12:4-17.

16 Heady B. Old age is not downhill: the satisfactions and well-being of older Australians. Aust J Ageing 1999;18(suppl):32-37.

17 Isacsson G, Bergman U, Rich CL. Epidemiological data suggest antidepressants reduce suicide among depressives. I Affect Disord 1996;41:1-8.

18 Hickie IB, Davenport TA, Naismith SL, Scott EM, Hadzi-Pavlovic D, Koschera A. Treatment of common mental disorders in Australian general practice. Med J Aust 2001;175(suppl):S25-30.

19 Preskorn SH. Antidepressant drug selection: criteria and options. J Clin Psychiatry 1994;55:6-22.

20 Mackay FR, Dunn NR, Martin RM, Pearce GL, Freemantle SN, Mann RD. Newer antidepressants: a comparison of tolerability in general practice. BrJ Gen Pract 1999;49:892-6.

21 Jorm AF, Medway J, Christensen H, Korten AE, Jacomb PA, Rodgers B. Public beliefs about the helpfulness of interventions for depression: effects on actions taken when experiencing anxiety and depression effects on actions taken when experiencing

22 Britt H, Miller GC, Knox S, Charles J, Valenti L, Henderson J, et al . General practice activity in Australia 2000-01. Canberra: Australian Institute of 
Health and Welfare, 2001. (AIHW Catalogue Number: GEP 8, General Prath and welfare,

23 Naismith SL, Hickie

, Scott FM, Davenport TA. Effects of mental health training and clinical audit on general practitioners' management of common mental disorders. Med JAust 2001;175(suppl):S42-7.
24 Hickie IB. Depression and the community. Responding to the Australian experience of depression. Med J Aust 2002;176(suppl):S61-2.

(Accepted 13 March 2003) 